УДК 78.01-791.43.01

\title{
А. Овсянникова-Трель
}

\section{КУЛЬТУРОЛОГИЧЕСКИЕ АСПЕКТЫ ИССЛЕДОВАНИЯ КИНОМУЗЫКИ УКРАИНСКИХ КОМПОЗИТОРОВ}

\begin{abstract}
В статье рассматривается значение киномузыки в творчестве украинских композиторов в культурологическом контексте. Обсуждаются истоки композиторской практики в украинском кинематографе и их влияние на последующее развитие киномузыки. Сделана попытка обозначить проблемное поле культурологического исследования киномузыки украинских композиторов (киномузыка как звучащая реальность, коммуникативная функция музыкально-звукового образа и т. п.), в том числе современных - В. Сильвестрова, О. Кивы, В. Губы, А. Щетинского.

Ключевые слова: киномузыка, кинематограф, музыкально-звуковой образ, композиторская практика, авторская музыка, прикладная музыка.
\end{abstract}

В богатом и разнообразном мире музыкальной культуры Украины $\mathrm{XX}$ столетия творчество композиторов-профессионалов, представляющих национальную академическую традицию, имеет первостепенное значение. С именами классиков украинской музыки - Бориса Лятошинского, Платона и Георгия Майбород, К. Данькевича, Игоря Шамо, Ивана Карабица, Евгения Станковича, Мирослава Скорика, Владимира Губы, Валентина Сильвестрова - связаны наши привычные, традиционные представления о национальном своеобразии и самобытности украинской музыки. И так же привычно мы знакомы преимущественно с традиционными жанрами музыкального искусства, составляющими основную и, несомненно, самую ценную часть творческого наследия перечисленных композиторов - симфонии, оперы, камерная музыка, хоровые произведения.

Однако в творчестве практически каждого из названных композиторов присутствует менее серьёзный (в силу своей прикладной функции) и более простой (в сравнении с авторской классикой) вид музыкального искусства, который раскрывает нам ещё одну сторону их дарования. Речь идёт о киномузыке, которая, как оказывается, составляет некую «постоянную величину» в украинской композиторской практике второй половины XX века и современности. К прикладному жанру «музыки для кино» украинские композиторы обращаются достаточно часто, однако эта тема до сих пор не стала предметом научного обсуждения (на сегодняшний день есть с десяток публикаций, освещающих вопросы киномузыки украинских ав-

(C) Овсянникова-Трель А., 2015 
торов). Одним из самых значительных опытов в этом плане явилась попытка украинского искусствоведа Ольги Литвиновой систематизировать музыку в украинском кино - каталог «Музыка в кинематографе Украины» [1], в котором собраны персоналии авторов музыки к фильмам, снятым на украинских киностудиях периода от немого кино до наших дней. Этот каталог был издан в Киеве в 2009 году и на сегодняшний день является уникальным образцом исследования проблемы развития киномузыки в Украине.

Учитывая тот факт, что область кинематографии является одним из наиболее обширных пластов современной культуры, а искусство кино стало неотъемлемой составляющей жизни современного человека, несомненную актуальность для исследования представляет и киномузыка, как неотъемлемая часть самого массового и популярного из искусств. Поэтому целью данной статьи явилось панорамное обозрение украинской киномузыки как существенной и малоизученной части композиторской практики второй половины XX века и современности. В рамках данного материала стояла задача обрисовать предметное поле возможных исследовательских подходов к данной теме.

Первые опыты украинских композиторов в создании музыки для кино относятся к концу 1920-х годов, этому же времени соответствуют издания оригинальных композиций известных украинских авторов (М. Вериковский, Б. Яновский, М. Коляда), предназначенных для звучания в фильме. Тот факт, что Украинское общество драматургов и композиторов считало целесообразным издавать музыкальные сочинения прикладного статуса, представляющие «второй план» композиторского дарования, говорит о многом. Прежде всего - о месте и роли кинематографа в украинской культуре соответствующей эпохи. В эпоху советского искусства кинематографу придавалось огромное значение, его воздействие на «массовое» сознание было неоспоримо: собственно вся тематика и образность советского кино выполняла воспитательно-назидательную функцию, «...киноэкран рассматривали как одно из серьёзных средств общеобразовательного и даже музыкального воспитания», - пишет О. Литвинова [1, с. 11]. И далее: «Задание кинематографа с точки зрения партийно-директивных органов заключалось в «активизации общественной жизни», «формировании мировоззрения каждого гражданина на идеологически правильных основаниях», обеспечении патриотического сознания в том числе» [1, с. 14]. Соответственно в культурно-идеологическом кон- 
тексте советского искусства на музыку, созданную для кино, возлагались такие же серьёзные задачи и функции, как и в целом на самое важное «из народных» и массовых искусств. В этом смысле культурная идея своего времени нивелировала прикладной жанровый смысл киномузыки, возводя его в ранг идеологически корректированной звучащей реальности. И это является существенной стороной развития «музыки в кино» в условиях советской культуры, тем смысловым вектором, который определяет своеобразие не только украинской, но советской киномузыки в целом, в том числе её выраженную компенсативную функцию (см. об этом [2]).

Известно, что на украинских киностудиях работали самые известные фигуры украинской музыкальной культуры - такие композиторы как Л. Ревуцкий (работавший также долгое время дирижёром в кинотеатрах Киева) и Ю. Мейтус, неоднократно сотрудничавший с режиссёрами Одесской киностудии и являющийся автором музыки почти что к двум десяткам кинолент в лучших традициях советского реализма. У самых истоков истории украинской киномузыки стоял $B$. Косенко, в юности подрабатывавший тапёром в провинциальном житомирском кинотеатре и проводивший феноменальные эксперименты по «приспособлению» музыки Р. Вагнера к немому фильму «Нибелунги» (1924) культового немецкого режиссёра Фрица Ланга (композитор перекладывал вагнеровские партитуры для фортепианного ансамбля из трёх человек). В данном случае речь, конечно же, идёт не об авторской музыке в кинематографе, но об уникальном случае артистического энтузиазма и принципиально серьёзного отношения к «функциям музыки в кино» (которые сегодня лежат в основе научного подхода к киномузыке) и той стороне профессиональной деятельности композитора, которую часто расценивали как возможность дополнительного заработка.

Классик украинской композиторской школы Б. Лятошинский является автором музыки к 14 художественным фильмам, в основе которых - национальная история и её великие представители («Кармелюк», «Визволення», «Тарас Шевченко», «Григорий Сковорода»). Творчество Б. Лятошинского, связанное с кинематографом, развивалось в русле идеологической и эстетической концепции советского киноискусства, что характерно для большинства авторской киномузыки 1930-х годов, военных и послевоенных лет, в том числе и для классиков этого жанра Д. Шостаковича (музыка к фильмам «Простые люди», «Молодая гвардия», «Падение Берлина») и С. Проко- 
фьева (музыка к фильмам «Александр Невский», «Партизаны в степях Украины», «Котовский», «Лермонтов», «Иван Грозный»).

Национальное своеобразие украинского кино данной эпохи, развивавшегося в контексте серьёзности и масштабности культуротворческих устремлений советского кинематографа, в немалой степени зависело и от музыкального облика упомянутых фильмов. И это вполне закономерно: авторами музыки в данном случае оказывались композиторы-профессионалы высочайшего уровня, которые обладали талантом «перевода» культурных идей своего времени на язык музыки и сумели полноценно и адекватно в художественном смысле озвучить эти идеи - монументально, не без пафоса, но всегда убедительно с точки зрения композиторского профессионализма, соответствия режиссёрскому замыслу и духу времени. И музыкально-звуковые образы украинского кино, созданные Б. Лятошинским и Ю. Мейтусом, например, в полной мере соответствовали образам психологической, эмоциональной, эстетической, духовной жизни своего времени. Это сообщает им высокий коммуникационный потенциал и утверждает главную функцию киномузыки данных композиторов - коммуникативную, которая изначально заложена в кино, как и в любом другом из искусств. «Одним из сущностных признаков экранных искусств, - отмечает А. Щербакова, - является установка на полноту репродуцирования реальности: онтологическая природа изображения - фотографичность. В то же время для авторов, работающих в кино, естественна индивидуальная субъективная позиция, т. е. активная интерпретация картины мира со скрытым стремлением достичь уровня креативности, присущего другим, традиционным развитым видам искусства. Подобная антиномическая ситуация не может быть успешно решаемой исключительно визуальными, изобразительными средствами - нужны дополнительные «подсказки», «указатели», «опоры», фокусирующие внимание зрителя в нужном направлении... В этой роли весьма успешно выступает звук, особенно музыка, которая может взять на себя решение информационных, художественных, психологических и иных задач любой сложности... $[4$, c. 2].

Высокий уровень профессионализма названных композиторов, который заметно «перекрывал» прикладной уровень создания музыки для кино, задал тот серьёзный и масштабный тон дальнейшему развитию киномузыки в творчестве украинских композиторов последующих поколений, который мы в рамках данной статьи поста- 
раемся схематично обозначить. Разговор о масштабности возникает не случайно: фильмография некоторых композиторов действительно поражает своими объёмами, что указывает на жанровую сферу киномузыки как константу в масштабах национальной композиторской школы.

Итак, Игорь Шамо написал музыку почти к 30 фильмам (среди которых и художественные, и документальные, и анимационные). Среди режиссёров, с которыми сотрудничал композитор, - Владимир Браун, Сергей Параджанов, Анатолий Слесаренко, Виктор Ивченко, Лесь Швачко, Тимофей Левчук. Самые известные фильмы с музыкой И. Шамо - «Дума о Ковпаке», «Цветок на камне» и «Андриеш», «Гори, моя звезда». Тема Великой Отечественной войны занимает значительное место в творчестве композитора: как известно, им написаны баллады «Бессмертный гарнизон», «Стоит над Волгою курган», «Баллада о солдатах», «Фронтовики», «Баллада о братстве», «Герои-города», «Вспомним друзей». Песни о войне звучат и во многих фильмах, к которым композитор писал музыку - «Их знали только в лицо», «Вдали от Родины», «Ночь перед рассветом», «От Буга до Вислы», «Дума о Ковпаке», «Карпаты, Карпаты...», «Командир корабля», «Ракеты не должны взлететь» и многих других.

Мирослав Скорик - автор музыки более чем к 40 фильмам, среди которых - «Тени забытых предков» (режиссёр Сергей Параджанов, 1964), «Живая вода» (режиссёр Григорий Кохан), «Личная жизнь» (реж. Владимир Довгань), «Высокий перевал» (реж. Владимир Денисенко). Самая известная киномузыка Мирослава Скорика - знаменитая Мелодия из фильма «Высокий перевал». Режиссёр фильма, не разделяя трактовки сценария, которую навязывала советская цензура, обратился к Мирославу Скорику с просьбой написать такую музыку к киноленте, которая смогла бы «рассказать» зрителю то, чего нельзя было показать. Изначально произведение было написано для флейты и фортепиано, но позже композитор сделал переработку для скрипки с фортепиано, и скрипки с оркестром. «Мелодия» часто используется сегодня без ведома и согласия автора в коммерческих целях (к примеру, в многосерийном фильме российско-украинского производства «Доярка из Хацапетовки», 2007).

Киномузыка представлена и в творчестве Валентина Сильвестров $a$ - композитора, представляющего не только современную украинскую музыку, но и значительного в репрезентации музыкальной культуры в общеевропейских масштабах. Творчество этого композитора в 
достаточной мере исследовано. Однако киномузыка В. Сильвестрова до сих пор не являлась предметом специального исследования в Украине. Композитором написана музыка более чем к десяти фильмам, среди которых «Пробивной человек», «Грачи», «Сад Гефсиманский» (режиссёр Ростислав Синько), «Время прощания (реж. Франсуа Озон). Сотрудничая с таким ярким режиссёром современности как Кира Муратова, киноленты которой сегодня органично вписаны в стилевой контекст европейского арт-хаусного кино, В. Сильвестров, так или иначе, обращается к художественным принципам постмодернистской культуры, в русле которой обычно рассматривают режиссёрские работы Муратовой. Сильвестровым написана музыка к таким фильмам как «Настройщик» (2004) и «Чеховские мотивы» (2002). Музыка как составляющий выразительно-смысловой элемент интеллектуального кино, несомненно, представляет культурологический интерес, поскольку функция музыкального ряда фильма состоит в создании полноты смысла комплексного аудио-визуального целого, которое в фильмах К. Муратовой всегда гипертрофированно в своей сложности и иногда абсурдности.

Композитор Олег Кива также известен своими многочисленными опытами в области «прикладного» жанра киномузыки. Окончив Киевскую консерваторию в 1971 году (класс Мирослава Скорика), он пишет не только балеты, камерные кантаты, концерты для фортепиано с оркестром, симфонии, камерные и хоровые сочинения, но также и музыку к кино- и телефильмам. Среди самых известных фильмов с музыкой О. Кивы - «Сердца трёх» (по Джеку Лондону, 1992), украино-швейцарский фильм «Тупик» (1998), а также популярные сериалы «Графиня де Монсоро» (1997), «Убить змея», «Кукла», «Пепел феникса». В общей сложности композитором написана музыка к 36 фильмам, среди которых, примерно с 1990-х годов, преобладают сериалы, столь популярные в современной массовой культуре. Преимущественно музыка О. Кивы написана к фильмам российских режиссёров, среди которых особенно стоит выделить Владимира Попкова, сотрудничество с ним составило своеобразный творческий тандем: большинство киноработ режиссёра озвучено именно музыкой украинского композитора.

Ещё одна интересная и, несомненно, заслуживающая внимания фигура в мире украинской киномузыки - Владимир Губа - композитор, который, по существу, специализировался на создании киномузыки, она составляет основную часть его творчества. После 
окончания в 1977 году Киевской консерватории (он учился в классе Лятошинского и Штогаренко), он работал музыкальным редактором киностудии «Укркинохроника». В. Губа - автор музыки более чем к сорока фильмам (художественным и документальным, а также мультфильмам). Самые известные из них - «Олеся», «Захар Беркут», «Каштанка» (1970-е годы), «Завтра начинается сегодня» (1983), «Больше, чем любовь» (2010), мультфильмы «Светлая личность» и «Одноразовая вечность» (2000-е годы). Сегодня композитор является почётным членом Национального союза кинематографистов Украины, а также Творческого союза «Кинематография славянских народов».

В творчестве известного молодого украинского композитораавангардиста Александра Щетинского, который в конце 1980-х годов был одним из организаторов фестивалей современной камерной музыки в Украине и России, активно сочинял и пропагандировал «новую музыку», также присутствует обращение к киноискусству. А. Щетинский - автор музыки к двум фильмам молодого украинского режиссёра Игоря Подольчака, который сегодня представляет линию экспериментального кино в Украине. Фильм «Менины» (2008) явился первым украинским проектом, принявшим участие в конкурсе Роттердамского кинофестиваля в 2008 году (позднее этот фильм принял участие более в чем 27 международных кинофестивалях). Отказываясь от линейного сюжетного действия, режиссёр как бы затягивает зрителя в странную атмосферу фильма, предлагая ему роль «невидимого наблюдателя», лишённого каких-либо установок на восприятие происходящего. Таким образом, зритель в какой-то момент перестаёт чувствовать грань между собственной рефлексией и рефлексиями персонажей фильма. Именно в этой точке «стирания граней» становится очевидной связь фильма и одноимённой картины Диего Веласкеса, к которой апеллирует режиссёр. Поскольку главный персонаж фильма Мать является бывшей виолончелисткой, а Сын в детстве учился игре на фортепиано, основная часть музыки создана именно для этих инструментов. Не отбрасывая полностью традиционного использования музыки в кино как фона для диалогов или средства эмоциональной окраски кадра, режиссёр и композитор сосредоточили внимание на самостоятельной роли музыки как смыслового контрапункта к словам и видеоряду. Во многих сценах музыка выходит на первый план и соединяется с шумами, как природными, так и созданными искусственно, которые смонтированы 
по музыкальным принципам. Поэтому весь звуковой ряд фильма можно рассматривать как целостную звуковую инсталляция. Для 15-минутной сцены фильма (воспоминания и бред Сына), которая не содержит ни одного слова, Александром Щетинским была создана Соната для виолончели и фортепиано - самостоятельная концертная композиция, которая может исполняться отдельно от фильма. Стилистическая палитра музыки, соответственно многоплановой смысловой структуре фильма, довольно широка - от барочных, классических и позднеромантических аллюзий до сложной серийности и сонористики. Однако сам композитор утверждает, что избегает коллажного объединения разных стилей, стремясь к их интеграции и синтезу.

В фильме «Бред» (2012) режиссёр и композитор изначально планировали использовать Dies irae (День гнева), как часть католической мессы. Поэтому были написаны шесть законченных инструментальных частей, названных соответственно разделам латинского текста мессы: Dies Irae, Quantus tremor, Mors stupebit, Ingemisco, Tuba mirum и Lacrimosa. При этом Щетинский ограничился средствами симфонического оркестра и не использовал ни текста, ни вокала. Музыка не содержала прямой иллюстративности и, в частности, благодаря авангардным стилевым приёмам парадоксально соединялась с названиями частей мессы, апеллируя к принципам сюрреализма, которые полностью отвечали эстетике фильма. Однако в процессе работы авторы решили использовать только две музыкальные части - Mors stupebit в начале фильма (начальные титры) и Dies irae на конечных титрах. Во время разворачивания действия фильма музыка вообще не звучит. Единственное исключение - молитва-речитатив священника, где использован текст Dies irae (в озвучивании этого эпизода принимал участие сам композитор). Благодаря этому начальный и конечный музыкальные фрагменты приобрели дополнительное драматургическое значение: введение в «проблематику» фильма (эффект настраивания на соответствующую эстетическую «волну») и смысловое обобщение. В то же время молитва Священника эту проблематику конкретизирует. Киномузыка А. Щетианского обладает достаточной сложностью и оригинальностью за счёт своей смысловой насыщенности, при этом она не «давит» на зрителя, но никогда не теряется из «поля зрения», часто опровергая знаменитую мысль Ю. Тынянова: «Музыка в кино поглощается - вы её почти не слышите и не следите за ней. (И это хорошо - музыка, которая сама 
по себе интересна, - вас отвлечет от действия; она вторгнется в кино как чужая)» $[3$, с. 90].

Таким образом, можно утверждать, что киномузыка представляет весьма обширную область в творчестве украинских композиторов второй половины XX века и современности. И если в одних случаях музыка, созданная для фильма, является лишь частным проявлением творческого дарования композитора (как у Бориса Лятошинского, Мирослава Скорика, Валентина Сильвестрова, например), то в других - мы имеем дело с настоящими специалистами в этой сфеpe, у которых основной массив сочинений связан именно с «производством» музыки для кино (Владимир Губа, Олег Кива). И в этом случае мы не случайно употребляем понятие «производство», поскольку обилие музыки к сериалам, например, в творчестве Олега Кивы, свидетельствует об органичной вписанности украинской композиторской практики в культурный контекст современности, о диалоге творческой индивидуальности композитора, воспитанной на классической музыкальной традиции, с массовыми популярными жанрами кино.

Не менее интересным аспектом изучения киномузыки украинских композиторов может явиться география режиссёров, с которыми они сотрудничали: перечисленные нами фильмы говорят о том, что украинские композиторы писали музыку к фильмам режиссёров, представляющих различные национальные традиции - русскую, грузинскую (С. Параджанов), французскую (Франсуа Озон), и конечно же, украинскую.

Совершенно отдельную тему исследования киномузыки украинских композиторов может составить проблема музыкального ряда в условиях специфической и усложнённой современной кинопоэтики и экспериментального кино, как например, в фильмах Киры Муратовой и Игоря Подольчака, с которыми сотрудничали Валентин Сильвестров и Александр Щетинский. Проблематику киномузыки можно расширять и дальше, поскольку эта область композиторской практики в Украине оказалась представлена не фрагментно, а в некоторой мере симптоматично, демонстрируя некоторую постоянность. Мы лишь стремились обозначить контуры данного явления, которое представляет несомненный интерес для исследования современной украинской культуры. 


\section{СПИСОК ЛИТЕРАТУРЫ}

1. Литвинова О. У. Музика в кінематографі України. Каталог. Ч. 1 : Автори музики художньо-ігрових фільмів, які створювалися на кіностудіях України / О. У. Литвинова. - Київ, 2009. - 456 с.

2. Овсянникова-Трель А. А. Киномузыка как культурный феномен современности / А. А. Овсянникова-Трель // Міжнародний вісник: культурологія, філологія, музикознавство : [зб. наук. ст.]. - Київ: Міленіум, 2015. - Вип. II (5). - C. 163-168.

3. Тынянов Ю. Поэтика. История литературы. Кино / Ю. Тынянов. - М.: Наука, 1977. - 576 с.

4. Щербакова А. А. Музыка как фактор общения в отечественном кино конца 80-90-х годов [Электронный ресурс] / А. А. Щербакова // Вестник ЛГУ им. А. С. Пушкина. - 2008. - № 4 (17). - Режим доступа : http:// cyberleninka.ru/article/n/muzyka-kak-faktor-obscheniya-v-otechestvennomkino-kontsa-80-90-h-godov

Овсяннікова-Трель О. Культурологічні аспекти дослідження кіномузики украӥнських композиторів. У статті розглядається значення кіномузики в творчості українських композиторів в культурологічному контексті. Обговорюються витоки композиторської практики в українському кінематографі та їх вплив на подальший розвиток кіномузики. Зроблено спробу окреслити проблемне поле культурологічного дослідження кіномузики українських композиторів (кіномузика як звукова реальність, комунікативна функція музично-звукового образу і т. п.), в тому числі сучасних - В. Сильвестрова, О. Ківи, В. Губи, О. Щетинського.

Ключові слова: кіномузика, кінематограф, музично-звуковий образ, композиторська практика, авторська музика, прикладна музика.

Ovsyannikova-Trell O. Cultural aspects of the study of film music by Ukrainian composers. The article discusses the importance of film music in the works of Ukrainian composers in a cultural context. Discusses the origins of the composer's practice in Ukrainian cinema, and their influence on the subsequent development of film music. An attempt was made to identify the problem field of cultural studies of film music by Ukrainian composers (film music at a sounding reality, communicative function of music and sound image, etc.), including modern - V. Silvestrov, O. Kiva, V. Guba, A. Shchetynsky.

Keywords: film music, film, musical and sound image, compositional practice, author's music, applied music. 